\title{
CONDICIONANTES TERRITORIAIS PARA FORMAÇÃO, DESENVOLVIMENTO E ESTRUTURAÇÃO DE ARRANJOS PRODUTIVOS LOCAIS: UM ESTUDO COMPARATIVO EM APLS DE CONFECÇÃO DO ESTADO DE MINAS GERAIS
}

\section{Fabrício Molica de Mendonça}

Doutor em Engenharia de Produção pela Universidade Federal do Rio de Janeiro - UFRJ

Professor da Universidade Federal de São João Del-Rei - UFSJ

fabriciomolica@yahoo.com.br

\section{Marília Paula dos Reis Teixeira}

Doutoranda em Administração da Universidade Federal de Lavras - UFLA

Tutora da Universidade Federal de Lavras - UFLA

marilia0203@yahoo.com.br

\section{Denise Carneiro dos Reis Bernardo}

Doutora em Administração pela Universidade Federal de Lavras - UFLA

Professora da Universidade Federal de São João Del-Rei - UFSJ

denisecarneiroprof@yahoo.com.br

\section{Henrique Pereira da Fonseca Netto}

Doutor em Economia Publica Planejamento Econometria pelo Université Paris 1, Paris Professor da Universidade Federal do Rio de Janeiro - UFRJ

henriquenettoeco@yahoo.com.br

\section{RESUMO}

Este estudo trata de investigação sobre os Sistemas Territoriais de Produção no âmbito de Arranjos Produtivos Locais (APLs) de confecções de Minas Gerais, aprofundando sobre a formação dessas firmas e seu desenvolvimento em aglomerados territoriais, para mostrar como esses territórios foram estruturados. Utilizaram-se como quadro teórico os condicionantes territoriais Marshallianos, Schumpeterianos, Transacionais e Institucionais. Fez-se uso de pesquisa qualitativa de cunho descritivo e o corpus estudado foi o APL de Muriaé e de São João Nepomuceno. A coleta de dados deu-se por meio de pesquisa bibliográfica e documental, entrevista semiestruturada e estruturada. Assim, foi possível identificar que ambos APLs são originários de uma firma inicial verticalizada. Apesar da identificação de um modelo de trajetória territorial para os APLs estudados, cada um possui características específicas sobre o número de agentes envolvidos e a forma de interação destes no território. No início, os condicionantes para surgimento dos APLs estiveram relacionados com as externalidades Marshallianas, criadas pelas empresas pioneiras. Com o tempo, outras externalidades surgiram: Schumpeterianas, para a criação de um ambiente inovativo; Transacionais, para a busca de maior interação entre as firmas, por meio da redução dos custos de transação; e Institucionais, relacionadas com modificações no ambiente institucional em que os APLs estão inseridos.

Palavras-chave: PMEs; Arranjos Produtivos Locais; Externalidades Territoriais. 


\section{INTRODUÇÃO}

As discussões sobre a importância do território como fator de desenvolvimento tem se intensificado a partir da análise do desenvolvimento econômico ocorrido na Terceira Itália (Itália) e no Vale do Silício (EUA), nas décadas de 70 e 80, originado pela concentração de pequenas e médias empresas (PMEs) organizadas na forma de redes relacionadas. Ressalta-se que essas regiões apresentaram altas taxas de crescimento em relação à média regional em seus respectivos países, bem como de outros países, num quadro de recessão econômica.

Em termos da análise espacial, houve um renovado interesse pelas ideias de Alfred Marshall ${ }^{1}$, que destacou os ganhos de eficiência decorrentes dos aglomerados produtivos, em que pequenas firmas se agrupam no que ele chamou de distritos industriais. Esses ganhos de eficiência se devem a externalidades positivas que geram rendimentos crescentes a partir da proximidade locacional. Destaca-se que existem outros conceitos para esse fenômeno, por isso aqui será utilizado o termo Arranjo Produtivo Local (APL), que é mais adequado ao corpus estudado.

$\mathrm{Na}$ literatura contemporânea sobre Economia Industrial, Economia Regional e Geografia Econômica, existem vários estudos que relatam as potencialidades de aglomerações locacionais de empresas. Parte significativa desses estudos trata de avaliações ex post de características de arranjos e suas contribuições para o desenvolvimento local/regional /nacional; da identificação de potencial de aglomerações empresariais em um setor; do emprego de metodologias de identificação da existência dessas aglomerações, e no Brasil existe uma tendência de pesquisas que relacionam redes e estratégias (Balestrin, Verschoore \& Reyes, 2010). Porém, há carência de estudos sobre a formação, o desenvolvimento e a estruturação desses arranjos, que podem fomentar políticas públicas para APLs mais eficazes.

Nesse cenário surge a pergunta que direciona este estudo: como os APLs foram estruturados dentro de uma lógica territorial, de modo que se tornassem fatores de localização capazes de atrair e manter empresas relacionadas entre si? Para tanto, tem-se como objetivo geral analisar dois arranjos produtivos locais da indústria tradicional, envolvendo confecções, pré-selecionados no Estado de Minas Gerais, de modo a identificar como esses APLs se formaram, como se desenvolveram e como estão estruturados.

Dessa forma, pergunta-se se há algum modelo de trajetória setorial e/ou territorial identificável, o que seria útil ao aprimoramento de políticas públicas direcionadas para o fortalecimento desse tipo de organização empresarial, que tem base na estruturação do território. Para atingir a finalidade proposta, o estudo envolve: a) a gênese desses APLs, por meio do levantamento do histórico de criação

Revista de Administração e Inovação, São Paulo, v. 9, n.3, p. 231-256, jul/set. 2012. 
e desenvolvimento de cada aglomerado; b) o processo de formação desses APLs; c) o levantamento dos agentes envolvidos; d) o relacionamento entre as empresas dentro dos aglomerados; e e) os tipos de externalidades territoriais que podem estar servindo de restrição para o desempenho desses APLs.

Desse modo, o presente estudo trata de investigação, até então pouco contemplada na literatura, sobre os Sistemas Territoriais de Produção no âmbito de APLs, do tipo Distritos Marshallianos e a sua versão italiana, aprofundando questões específicas referentes à formação das firmas e seu desenvolvimento em aglomerados territoriais. Destaca-se que o entendimento desse tipo de organização industrial/regional é importante na implementação de políticas de desenvolvimento de regiões e países, na busca de estratégias que visem acelerar o ganho de competitividade por meio da promoção, maturação e desenvolvimento de APLs.

\section{FUNDAMENTAÇÃO TEÓRICA}

Procurou-se fazer uma revisão bibliográfica, levantando os principais conceitos, definições e temas relacionados com as manifestações territoriais e os aspectos regionais, fornecidos pela literatura nacional e internacional. Assim, foram consolidados grupos de condicionantes territoriais que serviram de base para analisar a formação, o desenvolvimento e a estruturação de APLs de confecção no Estado de Minas Gerais.

\subsection{Definição e Características das Redes de Empresa}

$\mathrm{Na}$ busca pelo conceito do termo rede, Amato (2000, p. 46) mostrou que este é muito abrangente e complexo. As diversas definições apresentadas por autores como Ceglie e Dini (1999), Jarillo (1988), Podolny e Page (1998), e Ribault, Martinet e Lebidois (1995) mostram que as redes de empresas se caracterizam como grupo de organizações que colaboram entre si, para atingir objetivos comuns, por meio de relações horizontais/verticais.

Destarte, Britto (2002) define redes de empresas como arranjos interorganizacionais, baseados em vínculos entre empresas independentes, que dão origem a uma forma particular de coordenação das atividades econômicas. Inicialmente, as redes são formadas para reduzir o risco de perder investimentos, em virtude da relocalização de plantas produtivas em outras regiões com menores custos de operação (Markusen, 1996). Com isso, a rede pode proporcionar ganhos de escala, soluções em conjunto, aprendizagem, redução de custos e geração e manutenção de relações sociais 
(Verschoore \& Balestrin, 2008a), influenciando positivamente os resultados das PMEs associadas (Verschoore \& Balestrin, 2008b). No Brasil o tema rede é predominante em estudos interorganizacionais (Cunha \& Carrieri, 2003).

De acordo com Markusen (1996) um tipo de rede muito pesquisado se baseia na literatura sobre os distritos industriais, centrada na expansão de indústrias na Terceira Itália. A autora define um distrito industrial como uma área espacialmente delimitada, podendo ter como base recursos naturais ou certos tipos de indústria ou serviços. Assim, Markusen (1996) propõe tipologias, com base em distritos industriais: Marshalliano; Centro Radial; Plataforma Satélite e Ancorado pelo Estado. Outras tipologias também foram sugeridas como fenômeno de concentração espacial das firmas em determinadas regiões: Redes Topdown; Clusters Industriais; Milieu Inovadores; Sistema Produtivo Local e; APL. Interessa mencionar as características deste último.

Segundo o conceito da Rede de Pesquisa em Sistemas Produtivos e Inovativos Locais (Redesist), coordenada pelo Instituto de Economia da UFRJ, os APLs são “... aglomerados territoriais de agentes econômicos, políticos e sociais que apresentam vínculos mesmo que incipientes. Geralmente envolvem a participação e a interação de empresas" (Cassiolato \& Lastres, 2003, p. 27). Os autores esclarecem que essas empresas podem ser produtoras de bens e serviços, fornecedores, prestadoras de consultoria, comercializadoras, clientes, além de instituições públicas e privadas, que auxiliam os APLs de diversas formas.

Assinala-se que os APLs podem apresentar diferenciações significativas em virtude da sua capacidade dinâmica. Desse modo várias tipologias foram criadas, porém a mais conhecida na literatura é a adaptada Mytelka e Farinelli (2000, p.4), conforme Quadro 1.

\begin{tabular}{|l|c|c|c|}
\hline \multirow{2}{*}{\multicolumn{1}{c|}{$\begin{array}{c}\text { Existência de } \\
\text { liderança }\end{array}$}} & APLs & APLs & APLs \\
\cline { 2 - 4 } & Bnformais & Organizados & Inovativos \\
\hline Tamanho das firmas & Micro e pequena & Baixo a Médio & Alto \\
\hline Capacidade inovativa & Pequena & PME's & PME's e Grandes \\
\hline Confiança interna & Pequena & Alta & Contínua \\
\hline Nível tecnológico & Pequena & Média & Alta \\
\hline Linkages & Algum & Algum & Difundia \\
\hline Cooperação & Pequena & Alguma a alta & Alta \\
\hline Competição & Alta & Alta & Média a Alta \\
\hline Novos produtos & Poucos & Nenhum & Alguns continuamente \\
\hline Exportação & Pouca, nenhuma & Média a Alta & Alta \\
\hline
\end{tabular}


Desse modo, o termo APL não é visto como aglomeração em um estágio anterior de desenvolvimento, mas como um produto histórico do espaço social. Destarte, alguns APLs podem não progredir em direção a formas sistêmicas de organização produtiva local. Outros podem ter formas organizacionais mais desenvolvidas como verdadeiros sistemas produtivos localizados, como os APLs inovativos. Assim, neste trabalho optou-se pelo uso da terminologia Arranjo Produtivo Local. Essa nomenclatura, segundo Garcez (2003), não envolve juízo de valor quanto à ocorrência ou não de inovação, ou até mesmo de uma atuação sistêmica.

\subsection{A Concentração de Empresas em Aglomerações Produtivas}

A questão do saber onde produzir com a máxima eficiência, tendo em vista a distribuição espacial dos recursos produtivos e do mercado consumidor, tornou-se cada vez mais importante. Essas considerações permitiram o estabelecimento de teorias que buscam explicitar os processos de concentração ou desconcentração de empresas. Tais discussões têm como foco as relações que as firmas estabelecem com os espaços em que estão inseridas.

Para mostrar como a firma afeta e é afetada pelo espaço local/regional em que atua, Polèse (1998) afirma que há desenvolvimento numa região se indivíduos fundam empresas e realizam bons negócios que perpetuam no longo prazo. Porém, é necessário que a região seja dotada do chamado Espírito da Empresa que está relacionado com quatro elementos inter-relacionados: a) Geográfico; b) Socioeconômico; c) Sociocultural; e d) Institucional.

Assim, o processo aglomerativo pelo Espírito da Empresa estimula o crescimento das cidades e regiões. Nesse cenário, Krugman (1991) defende a tese de que a implantação das firmas obedece efeitos de feedback positivos de maneira que quanto mais se intensifica a concentração das firmas, mais importante será o tamanho do mercado, e quanto mais este aumente, mais permitirá induzir efeitos de arrastamento a montante e a jusante. Para explicar a dinâmica da localização industrial, o autor utiliza três argumentos de Marshall: a) permite a criação de um mercado de trabalho especializado e qualificado; b) favorece a produção de segredos tecnológicos de produção e de aprendizagem; e c) melhora a troca de informação.

No intuito de elucidar essa concentração geográfica, Krugman (1991) ainda apresentou um modelo de desenvolvimento endógeno, de uma geografia econômica de centro-periferia, baseado na interação econômica de escala, custos de transporte e migração. Por meio desse modelo, explica a aglomeração de empresas por meio da análise da interação da demanda, dos rendimentos crescentes e 
custos de transporte, que conduzem a um processo cumulativo de divergência regional. Parte do princípio que a produção industrial consiste num número de produtos diferenciados, cada um produzindo através de economias de escala, com uma estrutura de mercado monopolisticamente competitiva.

Nesse modelo, a sustentabilidade de um padrão centro-periferia é determinada pelo confronto de forças econômicas centrípetas e centrífugas. As forças centrípetas são representadas por linkages setoriais, spillovers de conhecimento e economias externas e de aglomeração. Essas forças são correspondentes aos encadeamentos a montante e a jusante de Hirschman (1958). Já as forças centrífugas são representadas por fatores que desestimulam a concentração industrial: preços de aluguéis, sunk costs e deseconomias externas.

A aglomeração de firmas propicia os retornos no nível da produção, o que diminui o custo de transporte e facilita a mobilidade dos fatores. Assim, a melhor localização está relacionada com a maximização do acesso dos bens aos mercados consumidores e aos ofertantes de bens intermediários. As externalidades surgem como consequência das interações do mercado envolvendo economias de escala em nível da firma individual, com isso há uma estrutura de mercado de concorrência imperfeita (Krugman, 1996).

No entanto, Krugman (1991) argumenta que, para compreender os determinantes da evolução de um sistema explicativo da localização industrial, é necessário conhecer o peso relativo dos parâmetros estudados por ele: demanda, economias de escala associadas à especialização, custos de transporte, forças centrípetas e centrífugas. Esses diferentes pesos explicam por que, em certos casos, a aglomeração é fruto de condições históricas iniciais de formação, como nos casos dos distritos industriais marshallianos e italianos e, em outros, fruto de modalidades de antecipação de agentes, como nos tecnopólis, nos polos científico-tecnológicos, dos parques industriais e das Zonas de Processamento de Exportações.

No caso dos distritos marshallianos, a organização industrial não se efetua unicamente por intermédio do mercado, mas articula-se essencialmente em torno de uma série de interdependências entre firmas, veiculadas pelas economias externas ou externalidades, sendo elas mesmas o resultado da proximidade espacial (Lemos, 2003).

Para Lemos, Santos e Crocco (2005) essas externalidades atuam como condicionantes territoriais que podem manifestar-se sobre o território de forma positiva, restritiva e negativa. Por isso, são consideradas como fator importante para explicar a formação, a estruturação, o crescimento e o desenvolvimento de APLs. Neste trabalho, as externalidades analisadas são as Marshallianas; Schumpeterianas; Transacionais e Institucionais (Quadro 2).

Revista de Administração e Inovação, São Paulo, v. 9, n.3, p. 231-256, jul/set. 2012. 


\begin{tabular}{|c|c|}
\hline Tipo & Condicionante \\
\hline \multirow{9}{*}{ Marshallianos } & - Disponibilidade de mão de obra, bem como sua qualidade e custo \\
\hline & - Presença de fornecedores de matérias-primas diversas disponíveis na região \\
\hline & - Presença de fornecedores de bens de capital \\
\hline & - Encadeamentos a jusante, a montante e horizontais extensivos \\
\hline & - Existência de programas governamentais \\
\hline & - Proximidade/vizinhança de mercados \\
\hline & - Disponibilidade de recursos naturais específicos localmente ou no entorno regional \\
\hline & $\begin{array}{l}\text { - Presença de infraestrutura física adequada e suficiente no seio da base produtiva } \\
\text { local (energia, telecomunicação, vias de acesso por meios de transportes etc.) }\end{array}$ \\
\hline & - Acesso fácil à informação \\
\hline \multirow{7}{*}{ Schumpeterianos } & - Existência de alto número de pessoas engajadas em atividades de design e inovação \\
\hline & - Elevado nível de qualificação da mão de obra \\
\hline & - Recorrentes trocas de pessoal entre fornecedores e usuários \\
\hline & - Universidades e Centros de pesquisa \\
\hline & $\begin{array}{l}\text { - Presença de Associações de Classe e Comerciais dedicadas assistência de rotina às } \\
\text { atividades técnicas, produtivas, comerciais e financeiras }\end{array}$ \\
\hline & $\begin{array}{l}\text { - Presença de associações de classe e comerciais para qualificação da força de } \\
\text { trabalho }\end{array}$ \\
\hline & - Presença de associações para capacitação tecnológica das firmas \\
\hline \multirow{8}{*}{ Transacionais } & $\begin{array}{l}\text { - Existência de cooperação entre firmas competidoras baseada em relações de } \\
\text { confiança altamente desenvolvidas e sedimentadas }\end{array}$ \\
\hline & - Presença de eficiência coletiva que reduz os custos de transação \\
\hline & - Utilização de colaboração horizontal \\
\hline & - Existência de contatos frequentes entre empresas formais e informais \\
\hline & - Presença de confiança recíproca \\
\hline & - Existência de contratos mais flexíveis \\
\hline & $\begin{array}{l}\text { - Influência da Governança Interna (GI) do APL em relação a facilidades para } \\
\text { elaboração de contratos mais flexíveis }\end{array}$ \\
\hline & - Contribuição da GI para facilitar compras, vendas e marketing em conjunto \\
\hline \multirow{4}{*}{ Institucionais } & $\begin{array}{l}\text { - Existência de um ambiente institucional que permite a redução da assimetria } \\
\text { de informação no SPL e redução de custos de transação }\end{array}$ \\
\hline & $\begin{array}{l}\text { - Criação de aspectos culturais que permitam estabelecer laços de confiança, } \\
\text { interação social, identidade e objetivos comuns }\end{array}$ \\
\hline & $\begin{array}{l}\text { - Existência de apoio das instituições políticas e sociais no desenvolvimento de } \\
\text { atividades de parceria e de instituições políticas e sociais para estimular a } \\
\text { transformação do SPL em sistemas mais amplos de inovação }\end{array}$ \\
\hline & $\begin{array}{l}\text { - Proximidade do APL de instituições de ensino, pesquisa e agentes } \\
\text { econômicos }\end{array}$ \\
\hline
\end{tabular}

Quadro 2 - Condicionantes Territoriais Utilizados para Analisar os APLs Estudados

Fonte: Elaborado pelos autores.

\section{PROCEDIMENTOS METODOLÓGICOS}

A presente pesquisa classifica-se como qualitativa, de cunho descritivo. Esse tipo de pesquisa é o mais adequado à compreensão de impactos sociais e culturais de um fenômeno, pois visa compreensão

Revista de Administração e Inovação, São Paulo, v. 9, n.3, p. 231-256, jul/set. 2012. 
e, em vez da generalização, tem o particular e o peculiar como focos, que se definem no seu desenvolvimento (Triviños, 1987).

A coleta de dados foi realizada por meio de: a) pesquisa bibliográfica, que visa ao conhecimento de contribuições científicas; b) pesquisa documental, que usa dados secundários, de fontes escritas e estatísticas realizadas por órgãos públicos (Black \& Champion, 1976); c) entrevista semiestruturada em função de itens verificados no referencial teórico, aplicada a conhecedores dos APLs, cujo roteiro foi elaborado seguindo recomendações de Barros e Lehfeld (2000) e que, segundo Trivinõs (1987), oferece ao informante liberdade cogente para o enriquecimento da investigação; d) entrevista estruturada, que foi elaborada em função de itens verificados por entrevista semiestruturada.

Conforme a disponibilidade de dados e o conhecimento dos informantes, o uso de dados primários (Quadro 3) e secundários variou entre APLs e afetou o número e a forma de preenchimento do roteiro único de entrevistas. Cabe destacar que, em Muriaé, para resgatar a história da primeira confecção, adotou-se o método de Depoimento Oral, em que se registra o conhecimento da história recente de um entrevistado, pois não havia registros escritos, e a fundadora ainda é viva.

Em virtude da necessária flexibilidade na obtenção das informações, no primeiro momento, a seleção de entrevistados foi feita por amostragem não probabilística do tipo Snowball, em que, segundo Malhotra (2001), a partir de referências ou informações obtidas em entrevistas anteriores, quantas vezes necessárias à complementação da pesquisa, por meio de indicação de novos possíveis respondentes pelos que já foram entrevistados.

As entrevistas semiestruturadas, embora seguindo o roteiro, realizaram-se por meio de conversas informais, dirigidas pelo entrevistador, para que o entrevistado se sentisse à vontade, sem ser limitado pelo número de perguntas. Durante a entrevista, documentos escritos foram apresentados aos entrevistados, para corroboração das respostas. As entrevistas foram gravadas e posteriormente transcritas. 


\begin{tabular}{|c|l|}
\hline APL & \multicolumn{1}{|c|}{ Fontes Primárias } \\
\hline \multirow{5}{*}{ Muriaé } & Entrevista semiestruturada aplicada ao (à): \\
& a) técnico do SEBRAE-MG; \\
& b) Fornecedor de máquinas e equipamentos; \\
& c) Secretário Municipal de Desenvolvimento; \\
d) Presidente da Delegacia Regional de Muriaé e Região; & e) Presidente do Circuito Polo da Moda; \\
& f) representante do SENAI e do CONDESC; \\
& h) proprietária da primeira confecção de Muriaé; \\
& i) Museólogo da Cidade; \\
& j) 6 empresários locais. \\
& Entrevista estruturada a 26 empresários locais \\
\hline \multirow{5}{*}{ São João Nepomuceno } & Entrevistas semiestruturadas aplicadas ao (à): \\
& a) gestor do SEBRAE-MG e do SENAI/SESI; \\
b) presidente do SINDIVEST; \\
c) presidente da Agência de Desenvolvimento; \\
d) 8 (oito) empresários locais, de empresas líderes do arranjo; \\
Entrevista estruturada aplicada a 20 empresários locais. \\
\hline
\end{tabular}

Quadro 3 - Fontes Primárias de Coleta de Dados dos APLs Pesquisados

Fonte: Dados da pesquisa

As empresas foram contatadas por telefone e email. A aplicação do questionário e a entrevista foram realizadas com as empresas que concordaram participar da pesquisa. Do total de empresas formais, foram entrevistadas $11 \%$ (26) em Muriaé; e $21 \%$ (20) em São João Nepomuceno. Esses percentuais, em função do número de empresas associadas aos órgãos de animação e apoio, representam: 52\% em Muriaé e 33\% em São João Nepomuceno.

Para checar se o número de entrevistas era suficiente, foi utilizado o raciocínio de Richardson (2007) para amostra estratificada proporcional, em que se toma uma fração de amostragem para cada estrato que seja semelhante à proporção que ele ocupa no universo. Assim, escolhendo-se 5\% da população de cada estrato, seria o bastante. No caso da pesquisa, optou-se por estratificar a população em virtude da classificação de empresas, relacionada com o número de empregados. Como medida de segurança, estabeleceu-se um mínimo de entrevistas igual a $10 \%$ do total de empresas formais em cada APL.

\section{RESULTADOS E DISCUSSÕES}

\subsection{Origem, Evolução e Estruturação dos APLs de Confecções Mineiros}


O desenvolvimento das atividades em Muriaé fez surgir condições que favoreceram a emergência do aglomerado, como existência de uma força de trabalho especializada, oportunidades de mercado e demanda e acesso a mercados. Nessa localidade, as empresas concorrentes foram criadas por ex-empregados do setor de produção, que, após um tempo de trabalho, adquiriram conhecimentos e abriram seus próprios negócios com recursos financeiros próprios. Nessa cidade, a Malharia Galante trouxe pessoas para treinamento e capacitação de mão de obra, desenvolveu mercado comprador na região e estabeleceu relações com a população local, por meio do treinamento de donas de casa nas atividades de costura e bordado. Com intensificação das vendas, por meio de representantes de vendas que levavam mercadorias para outras regiões do Estado e do País, houve a necessidade de ampliação das confecções domésticas, transformando-as em produção industrial. Assim, surgiu número considerável de confecções ao longo dos anos 60 e 70. Porém, o crescimento do número de empresas no aglomerado se deu na década de 80, quando ocorreu queda na atividade principal da cidade, que estava relacionada com pequenas oficinas mecânicas.

Em São João Nepomuceno a proliferação das empresas está relacionada a um acidente histórico, provocado pelo fechamento da empresa principal. Nessa cidade, paralelamente às sucessivas crises da empresa Sarmento ao longo dos anos 60, pequenas fábricas de roupas surgiram naturalmente, no seio das residências familiares, aproveitando a facilidade de obtenção da matéria-prima tecido (da Sarmento) e as habilidades das mulheres em relação à costura, como resposta à situação crítica que se estava vivendo. O fechamento da Sarmento na década de 70 levou parte da mão de obra familiar desempregada a ser absorvida pelas confecções e, com a ampliação de vendas, principalmente para outras localidades, houve a contratação de mão de obra e a transformação da produção doméstica em industrial.

Assim, nos dois APLs, a origem da aglomeração de empresas de um mesmo ramo de atividade, apresentando vantagem competitiva locacional, está relacionada com uma empresa verticalizada e estruturada sob a lógica funcional. Tais empresas - a Malharia Galante em Muriaé e a Companhia Fiação e Tecidos Sarmento em São João Nepomuceno - foram responsáveis, cada uma em sua localidade, por moldar a base produtiva do território. A gênese desses APLs revela o potencial empreendedor dos territórios em que se encontram, pois observou-se que tais arranjos não surgiram dos estímulos do planejamento público, mas de fontes endógenas e auto-organizativas.

É comum na indústria tradicional a formação de aglomerados produtivos provenientes da criação de empresas por ex-empregados de empresas locais, originários de uma empresa principal. Esse surgimento de empresas ocorre ou por acidente histórico, quando a empresa principal deixa de existir ou por evolução, quando ex-empregados, movidos pelo conhecimento adquirido, acabam

Revista de Administração e Inovação, São Paulo, v. 9, n.3, p. 231-256, jul/set. 2012. 
criando empresas concorrentes ou complementares. Isso pode ser observado nos estudos de Campos, Cário e Nicolau (2000); Crocco, Santos, Simões e Horácio (2001); Cunha, Pereira e Cassaroto (2006); Kraemer (2007); Maia (1994); e Piore e Sabel (1984).

Em todas as localidades estudadas por esses autores, a formação dos aglomerados se deve a condicionantes territoriais. Contudo, a maioria desses estudos não especifica os condicionantes territoriais que serviram para a criação e o desenvolvimento de empresas na região. Assim, apesar de diferirem de local para local, a investigação desses condicionantes é um bom caminho para compreender a formação, o desenvolvimento e a maturação dos APLs.

Nos dois APLs, a aglomeração territorial aumentou o fluxo de serviços. Assim, surgiram representantes comerciais e de matérias-primas, assistência técnica, serviços de transporte, permitindo que as empresas passassem a ter o mesmo acesso a esses itens. Isso atraiu novas empresas, porém, tal crescimento se deu de forma desorganizada.

Durante esse período verificou-se tanto a especialização produtiva quanto a prática de fabricação de produtos homogêneos, por meio da cópia de produtos. Assim, houve o acirramento da concorrência com base em preços, em virtude da livre circulação da informação, da mobilidade dos fatores de produção, do acesso à tecnologia rudimentar e da baixa barreira à entrada de empresas, dificultando o inter-relacionamento entre as empresas.

O desenvolvimento dos dois APLs esteve atrelado a eventos que geraram bifurcações na sua trajetória histórica, que estão relacionados a mudanças na organização industrial e tecnológica. Em Muriaé o crescimento desordenado de confecções, em 1980 e meados de 1990, aliado ao fortalecimento de outros polos da moda, fizeram com que os empresários percebessem a necessidade de juntar esforços para enfrentar os desafios. A partir da criação da pronta-entrega, as discussões dos empresários em relação à busca de soluções em conjunto e de interesse do poder público local fizeram surgir, a partir de 1999, várias entidades de animação: a Delegacia Regional de Muriaé e Região; o Conselho de Desenvolvimento Econômico e Social do Setor de Confecções (CONDESSC); a Secretaria Municipal de Desenvolvimento Econômico (SMDE); e o Serviço Brasileiro de Apoio às Micro e Pequenas Empresas (SEBRAE).

Em São João Nepomuceno, o crescimento desorganizado das confecções ocorreu até início dos anos 80, quando a Mesbla, uma grande empresa comercial, começou a coordenar e controlar as empresas. Por meio de contratos de produção, firmados junto às empresas formais da cidade, a Mesbla coordenava a produção destas. Nesse mesmo período, surgiu um número significativo de empresas informais, que davam suporte às empresas formais, na facção de peças, principalmente quando o volume de pedidos era superior à sua capacidade produtiva. Assim, iniciou-se uma parceria entre 
empresas formais e informais, que existe até hoje. O crescimento do setor e os problemas relacionados com os altos índices de inflação em 1980 fizeram com que fosse criada a associação de classe para os empresários locais, denominada ASSIMODA. Em meados dos anos 1990, foi substituída pelo SINDIVEST. A relação com a Mesbla durou até 1996, quando esta faliu, trazendo consequências às empresas do arranjo, principalmente falência. Isso fez com que os empresários começassem a juntar esforços para enfrentarem a crise. Como as empresas não trabalhavam com marcas próprias, a solução imediata foi a busca de outras empresas famosas que se dispusessem a produzir suas roupas no arranjo. Assim, começaram a produzir para várias empresas, como Zoomp, Triton, Fórum, Cantão, de modo a reduzir o risco em produzir apenas para um comprador. A partir de então, o SINDIVEST exerce o papel de animação e incentiva o desenvolvimento de marcas próprias.

Em Muriaé, houve a redução de cópia de produtos de empresas concorrentes formais e que são filiadas às instituições de coordenação. Porém, há ainda a prática de cópia de produtos, principalmente pelas empresas informais. Como forma de reduzir o efeito da cópia, as empresas têm investido no aumento da velocidade na inovação de design e mudança de materiais e estilo. A partir de então, houve surgimento de empresas especializadas em parte de processos produtivos. Em São João Nepomuceno, a prática de cópia de produtos foi reduzida desde o período Mesbla, porque as empresas formais sempre trabalharam para atender as exigências das Grifes, e as empresas informais foram criadas para dar suporte às formais.

Percebe-se então que a criação de empresas de animação é importante para o crescimento do APL, pois estimulam a capacidade de inovação. Esse crescimento se dá quando as novas empresas são atraídas pela renda e pelas áreas de mercado mais densas. O aumento da densidade de mercado poderá tornar a operação mais lucrativa no aglomerado, pelo maior consumo local e redução de custos de transporte, permitindo a recursividade do APL.

A organização desses aglomerados, então, fez com que as empresas passassem a se beneficiar da proximidade a outras firmas e obter ganhos com a melhoria na qualidade de mão de obra, custos na obtenção de matérias-primas, conhecimento tácito, dentre outros. Os linkages, gerados pelo próprio encadeamento das atividades produtivas e da proximidade das firmas, podem ser considerados responsáveis pelo crescimento e desenvolvimento dos APLs.

Os efeitos ou externalidades locais viabilizam uma escala mínima eficiente e, consequentemente, atrai outras empresas privadas pela possibilidade de lucro, com o oferecimento de uma gama de serviços à indústria, que aprimoram e integram a cadeia produtiva. Nos APLs estudados, além dos serviços ligados à atividade, houve a entrada de outras atividades de serviços gerais: bancos, assessoria de imprensa, gráfica.

Revista de Administração e Inovação, São Paulo, v. 9, n.3, p. 231-256, jul/set. 2012. 
Para que os APLs se tornassem mais competitivos, e não entrassem num círculo vicioso de estagnação ou regressão, foi necessário fazer parcerias com entidades públicas ou para-públicas de apoio e capacitação de mão de obra especializada e de gerência; de apoio às atividades de P\&D; de provimento de infraestrutura de suporte ao crescimento do APL; de captação de crédito e financiamentos; e de catalisadores da ação cooperativa e do investimento coletivo. Em Muriaé e São João Nepomuceno, há 13 parceiros, ressaltando que, em Muriaé, o peso maior de apoio é recebido da prefeitura municipal e de entidades locais.

Percebe-se que cada APL possui características específicas referentes ao número de agentes envolvidos e à interação desses agentes no território. Apesar de essas especificidades exercerem influência no desenvolvimento de cada um, o conjunto de todos os atores que fazem parte desses APLs pode ser visualizado pelo modelo desenvolvido por Fonseca:

\subsection{Sistema Territorial de Produção}

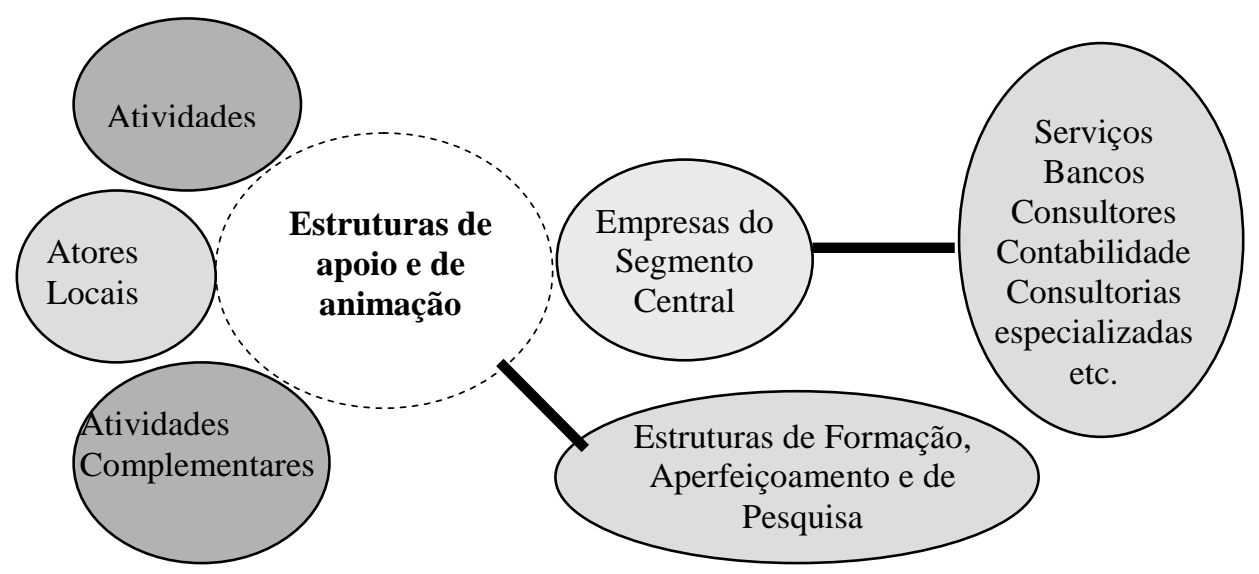

Figura 1 - Estrutura Geral dos Arranjos Produtivos Locais

Fonte: Adaptado de Fonseca (2002).

Aprofundando-se a análise de aglomerações produtivas, é possível mostrar que a interação destas com o ambiente é biunívoca, influenciando o grau de enraizamento ou ancoragem territorial, já que acaba criando externalidades positivas e negativas nesses territórios. Por exemplo, um ambiente de cooperação estimula a redução da verticalização das firmas, visto que os custos de transacionar com o mercado passam a ser menores. Assim, tem-se maior especialização produtiva das empresas, maior divisão do trabalho, ganho da produtividade. Isso estimula a criação de ativos intangíveis e circulação informal de conhecimento, levando ao seu crescimento e desenvolvimento. 


\subsection{Modelo de Formação e Desenvolvimento de APLs de Confecção em Minas Gerais}

A trajetória de formação e desenvolvimento dos APLs estudados está relacionada com condições que favoreceram a emergência do aglomerado, tais como: a existência de força de trabalho, de oportunidades de mercado e demanda, de acesso a mercados e de apoio de entidades de coordenação e suporte. Assim, fez-se o modelo que mostra essa trajetória (Figura 2). Ressalta-se que tal modelo pode ser usado para analisar outros APLs.

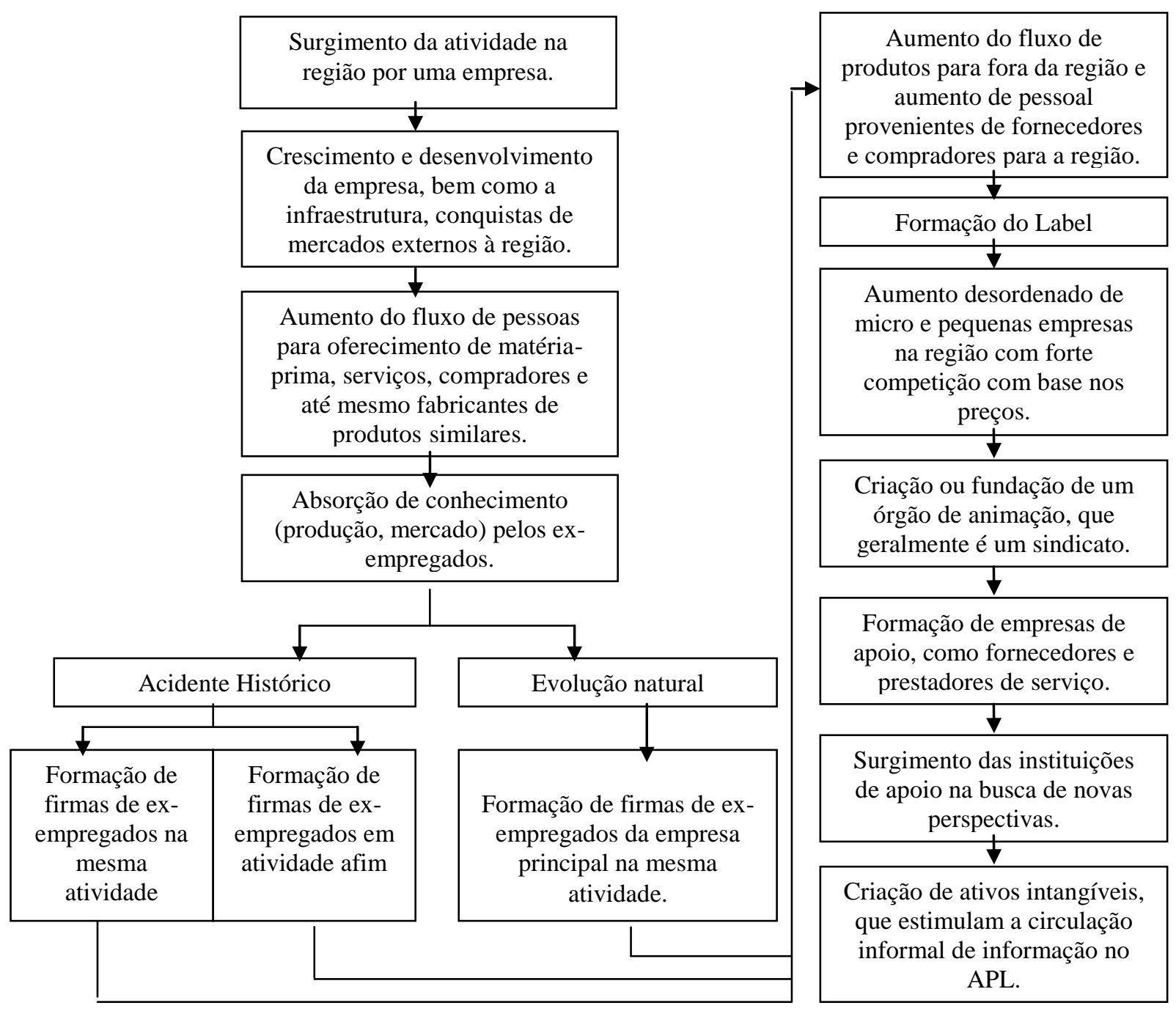

Figura 2 - Modelo de Formação e Desenvolvimento dos APLs de Confecção Mineiros

Fonte: Elaborado pelos autores. 
Ressalta-se que, apesar de se ter identificado um modelo de trajetória desses APLs, os aglomerados exibem diferentes graus de desenvolvimento, de integração a montante e a jusante da cadeia produtiva, de associativismo, de integração entre os agentes e instituições locais e de capacidade para inovação. Essas diferenças são resultantes da evolução histórica, da organização, do contexto social e cultural, da estrutura produtiva, das formas de inserção nos mercados interno e internacional, das estruturas de governança, da logística e de disseminação do conhecimento local. Então, para analisar a dinâmica dos APLs é necessário analisar os condicionantes territoriais, já que qualquer alteração nestes provoca diferença significativa entre os sistemas produtivos (Lemos et al., 2005).

\subsection{Condicionantes Territoriais de Incentivo ao Surgimento dos Aglomerados}

Percebe-se que a maioria dos condicionantes para surgimento dos APLs está relacionada com as externalidades Marshallianas, criadas pelas empresas pioneiras, tais como: infraestrutura, comunicação e energia; mão de obra especializada; acesso à tecnologia de produção; label territorial construído pela empresa principal. Com o tempo, outras externalidades são desenvolvidas, servindo como estímulos ou entraves aos APLs. Ressaltam-se os ganhos obtidos em se estabelecerem em aglomerados com presença de fatores de produção comuns, resultando aumentos de produtividade e queda de preços (Haddad, 1989).

A reunião dessas firmas na mesma região foi uma forma de apropriação de retornos crescentes obtidos nas etapas de produção, o que Marshall (1983) denominou de economias internas e externas. Assim, com o tempo, as vantagens competitivas foram fortalecidas, sendo atratores de novas empresas para o local, além de impulsionar produção e rentabilidade das existentes. Isso ocorreu em virtude: a) dos efeitos de encadeamentos de firmas a montante e a jusante no processo de produção; b) da aglomeração de trabalhadores especializados; c) das interações promotoras da inovação tecnológica. 


\begin{tabular}{|c|l|}
\hline Localidade & \multicolumn{1}{|c|}{ Condicionantes territoriais favoráveis ao surgimento do APL } \\
\hline Muriaé & $\begin{array}{l}\text { a) ambiente institucional desfavorável para a atividade mecânica, apresentando como } \\
\text { alternativa o trabalho nas confecções, iniciadas pelas donas de casa; } \\
\text { b) cultura do empresário local voltado para PMEs; } \\
\text { c) conhecimento difundido para grande número de donas de casa; } \\
\text { d) infraestrutura de comunicação, estradas, energia elétrica e serviços de transporte; } \\
\text { e) existência de fornecedores de máquina equipamentos. e assistência técnica, para } \\
\text { empresas do setor de confeç̧̃̃o na cidade; } \\
\text { f) existência de número significativo de vendedores e de representantes comerciais; } \\
\text { g) presença de um label territorial, construído ao longo dos anos de 1980, pelos } \\
\text { representantes de vendas e vendedores de produtos, fora da região; } \\
\text { h) exigência de baixo nível tecnológico, apresentando baixa barreira à entrada. }\end{array}$ \\
\hline São João Nep. & $\begin{array}{l}\text { a) presença de fornecedor da principal matéria-prima, tecido, pela Sarmento; } \\
\text { b) nome da cidade associado a tecidos e produtos de qualidade; } \\
\text { c) infraestrutura de comunicação, estradas, energia elétrica e serviços de transporte; } \\
\text { d) conhecimento sobre costura difundido para grande número de donas de casa, por } \\
\text { meio do processo de aprendizagem e rotina dentro das confecções existentes na cidade; } \\
\text { e) exigência de baixo nível tecnológico, apresentando baixa barreira de entrada; } \\
\text { f) formação de número significativo de vendedores e representantes comerciais; } \\
\text { g) disponibilidade de mão de obra; } \\
\text { h) qualidade da mão de obra compatível com as exigências da indústria. }\end{array}$ \\
\hline
\end{tabular}

Quadro 4 - Condicionantes Territoriais Favoráveis ao Surgimento das Pequenas Empresas dos APLs Estudados

Fonte: Elaborado pelos autores.

Além disso, a criação de firmas calcadas na exportação regional foi responsável pela garantia da sustentabilidade e de crescimento da região, já que, à medida que as empresas expandiam suas vendas para outras cidades e regiões, aumentavam o volume de produtos fabricados; atraíam mão de obra especializada em algumas atividades; aumentavam a renda das empresas; e, ainda, propiciavam surgimento de investimentos públicos em infraestrutura. Como consequência, a concentração de trabalhadores gerava externalidades no local, como a difusão do conhecimento tácito e a educação no ofício para a mão de obra, incitando uma identidade da região com a atividade empreendida. Isso fez com que mais empresas fossem atraídas para o negócio, mesmo porque as barreiras à entrada, em todos os dois APLs, eram consideradas baixas.

\subsection{Análise Comparativa dos Condicionantes dos APLs de Confecção de Minas Gerais}

Inicialmente, cabe informar que os dois APLs são caracterizados como de sobrevivência, conforme mostra o Quadro 5. 


\begin{tabular}{|c|c|c|}
\hline Itens analisados & Muriaé & São João Nepomuceno \\
\hline Tamanho das firmas & $\begin{array}{l}\text { Micro, pequenas e médias } \\
\text { empresas }\end{array}$ & Micro, pequenas e médias empresas \\
\hline Nível tecnológico & $\begin{array}{l}\text { Contínuo desenvolvimento } 30 \\
\text { empresas que se encontram no } \\
\text { estado da arte da tecnologia e } \\
\text { pequeno para o restante. }\end{array}$ & $\begin{array}{l}\text { Contínuo desenvolvimento para o grupo } \\
\text { de } 20 \text { empresas que se encontra no estado } \\
\text { da arte da tecnologia e pequeno para o } \\
\text { restante, dificultando a terceirização }\end{array}$ \\
\hline $\begin{array}{l}\text { rencial e } \\
\text { a }\end{array}$ & $\begin{array}{l}\text { Em expansão para o grupo de } 30 \\
\text { empresas e baixo para o restante. }\end{array}$ & $\begin{array}{l}\text { Em expansão para o grupo de } 20 \\
\text { empresas e baixo para o restante. }\end{array}$ \\
\hline Mão c & $\begin{array}{l}\text { Baixo nível de escolaridade, porém, } \\
\text { em constante treinamento (internos } \\
\text { e pelo SENAI e CONDESSC) }\end{array}$ & $\begin{array}{l}\text { Baixo nível de escolaridade e o } \\
\text { treinamento ocorre na empresa, pelos } \\
\text { aprendizados learning by doing e learning } \\
\text { by using. }\end{array}$ \\
\hline Barreiras & Baixa & Baixa \\
\hline Competição & $\begin{array}{l}\text { Média, tendendo a cooperar dentro } \\
\text { do grupo de } 30 \text { empresários, usam } \\
\text { da diferenciação de produtos e alta } \\
\text { nas demais empresas que praticam } \\
\text { cópia de produtos e concorrência } \\
\text { de preços. }\end{array}$ & $\begin{array}{l}\text { Média, uma vez que as empresas } \\
\text { diferenciam seus produtos, e grande parte } \\
\text { da produção é direcionada para clientes } \\
\text { específicos, localizados fora do território } \\
\text { do APL. }\end{array}$ \\
\hline $\begin{array}{l}\text { Cooperação entre as } \\
\text { empresas }\end{array}$ & $\begin{array}{l}\text { Dentro do grupo de } 30 \text { empresas, } \\
\text { há trabalhos de cooperação } \\
\text { horizontal: participação em feiras } \\
\text { especializadas; troca de } \\
\text { informações; ações conjuntas para } \\
\text { capacitação de mão de obra, } \\
\text { tentativas de formar consórcios de } \\
\text { exportação; elaboração conjunta de } \\
\text { catálogos. Nas demais empresas } \\
\text { não há essa cooperação. }\end{array}$ & $\begin{array}{l}\text { Baixa, porém, há iniciativas de } \\
\text { cooperação horizontal: participação em } \\
\text { feiras; troca de informações por meio de } \\
\text { reuniões, por } 20 \text { empresas; ações } \\
\text { conjuntas de marketing em conjunto de } 3 \\
\text { empresas que adquiriram a marca "Lápis } \\
\text { de Cor"; trabalho de design em conjunto } \\
\text { (8 empresas) e elaboração conjunta de } \\
\text { catálogos; feiras locais e participação em } \\
\text { feiras em outras regiões. }\end{array}$ \\
\hline to interfirmas & $\begin{array}{l}\text { Existem práticas de especialização } \\
\text { interfirmas: facção, bordados } \\
\text { mecânicos, bordados manuais. }\end{array}$ & $\begin{array}{l}\text { Existem práticas de especialização } \\
\text { interfirmas, tais como a facção, } \\
\text { especialização em bordados e em lavagem } \\
\text { de jeans. }\end{array}$ \\
\hline $\begin{array}{l}\text { o em produtos e } \\
\text { os }\end{array}$ & $\begin{array}{l}\text { Alta no grupo das } 30 \text { empresas e } \\
\text { baixa nas demais }\end{array}$ & $\begin{array}{l}\text { Alta no grupo de } 20 \text { empresas e baixa nas } \\
\text { demais }\end{array}$ \\
\hline Prática de exportação & $\begin{array}{l}\text { Quase inexistente (1 empresa } \\
\text { exporta regularmente, } 2 \text { exportam } \\
\text { espora-dicamente e } 5 \text { na fase } \\
\text { experimental) }\end{array}$ & $\begin{array}{l}\text { Praticamente inexistente }\left(\begin{array}{ll}1 & \text { empresa } \\
\text { exporta regularmente })\end{array}\right.\end{array}$ \\
\hline N. empresas informais & Alto & Alto \\
\hline $\begin{array}{l}\text { Coordenação das empresas } \\
\text { do APL }\end{array}$ & $\begin{array}{l}\text { Exercida pelo DRMR, } \\
\text { CONDESSC, SMDE e o SEBRAE- } \\
\text { MG, mas o número de associados é } \\
\text { pequeno, comparado com o número } \\
\text { de empresas do setor no APL. }\end{array}$ & $\begin{array}{l}\text { Exercida pelo SINDIVEST em conjunto } \\
\text { com o SEBRAE e com a Agência de } \\
\text { Desenvolvimento Regional. O número de } \\
\text { associados abrange } 100 \% \text { das empresas } \\
\text { formais. }\end{array}$ \\
\hline $\begin{array}{l}\text { Confiança para } \\
\text { especialização interfirmas }\end{array}$ & $\begin{array}{l}\text { Baixo, sendo necessários esforços } \\
\text { para essa confiança. }\end{array}$ & $\begin{array}{l}\text { Baixo, sendo necessários esforços para } \\
\text { aumentar essa confiança. }\end{array}$ \\
\hline
\end{tabular}

Quadro 5 - Comparação dos APLs de Muriaé e São João Nepomuceno, pela Classificação de Mytelka e Farinelli (2000)

Fonte: Elaborado pelos autores.

Para sumarizar os resultados relativos aos condicionantes territoriais, calculou-se a média das respostas obtidas junto à amostra por meio da escala Likert. Na escala utilizada, o 0 (zero) significa Revista de Administração e Inovação, São Paulo, v. 9, n.3, p. 231-256, jul/set. 2012. 
Condicionantes territoriais para a formação, desenvolvimento e estruturação de arranjos produtivos locais: um estudo comparativo em APLs de confeç̧ão do estado de Minas Gerais

que o condicionante é percebido como totalmente insatisfatório, e o 5 (cinco) significa que o condicionante é percebido como totalmente satisfatório. Nas análises foram utilizados também os dados descritivos colhidos na pesquisa. Doravante os resultados.

\subsubsection{Condicionantes marshallianos}

Analisando os condicionantes Marshallianos (Tabela 1), percebe-se que, nos dois APLs, a existência e o peso desses quase não se alteram. Em relação à qualidade da mão de obra, Muriaé apresenta melhor resultado, que pode estar relacionado ao maior número de instituições de capacitação de mão de obra especializada no território, enquanto a de São João Nepomuceno é basicamente treinada dentro das empresas. Quanto à disponibilidade de mão de obra especializada, tem-se que, com o aumento do volume de empresas, há carência de pessoal especializado, fazendo com que esses custos apresentem aumentos significativos.

Quanto aos fornecedores, Muriaé apresenta melhores condições, visto que os materiais e equipamentos são comercializados no território. Em São João Nepomuceno não há fornecedores locais, e sim apenas um fornecedor de máquinas e equipamentos.

Tabela 1 - Comparativo dos Condicionantes Marshallianos entre Muriaé e São João Nepomuceno

\begin{tabular}{l|c|c}
\multicolumn{1}{c|}{ Condicionantes Marshallianos } & $\begin{array}{c}\text { Muriaé } \\
\text { (média) }\end{array}$ & $\begin{array}{c}\text { São João Nep. } \\
\text { (média) }\end{array}$ \\
\hline Disponibilidade de mão de obra & 3,0 & 2,6 \\
\hline Qualidade de mão de obra & 2,5 & 2,0 \\
\hline Custo da mão de obra & 2,0 & 2,0 \\
\hline Presença de fornecedores de matérias-primas na região & 3,0 & 0,0 \\
\hline Presença de fornecedores de bens de capital & 3,0 & 2,0 \\
\hline Encadeamentos a jusante, a montante e horizontais extensivos & 2,5 & 2,0 \\
\hline Proximidade/vizinhança de mercados & 3,0 & 3,0 \\
\hline Presença de recursos naturais específicos localmente/entorno & 0,0 & 0,0 \\
\hline Presença de infraestrutura energia & 4,0 & 3,5 \\
\hline Presença de infraestrutura telecomunicação & 3,0 & 2,5 \\
\hline Presença de infraestrutura transporte & 3,0 & 3,0 \\
\hline Presença de infraestrutura estrada & 1,6 & 2,0 \\
\hline O acesso fácil à informação & 3,0 & 3,0 \\
\hline Label territorial como estratégia mercadológica & 3,5 & 3,5 \\
\hline Média dos pontos & $\mathbf{2 , 8 5}$ & $\mathbf{2 , 2 2}$ \\
\hline Fon Elat & & \\
\hline
\end{tabular}

Fonte: Elaborado pelos autores.

\subsubsection{Condicionantes schumpeterianos}

Nota-se que condicionantes Schumpeterianos também não apresentaram diferenças significativas entre os APLs (Tabela 2). A qualidade da mão de obra em ambos é aceitável, porém não 
possui qualificação elevada. Em Muriaé, o treinamento de mão de obra especializada é mais intenso, mesmo porque existe a preocupação dos órgãos de coordenação, juntamente com a sua Prefeitura Municipal. Em São João Nepomuceno, grande parte do aprendizado está relacionado com os tipos learning by doing e learning by using.

Quanto à proximidade com universidades e centros de pesquisa, São João Nepomuceno apresenta situação mais vantajosa, por sua localização geográfica próxima a Juiz de Fora, permitindo maiores contatos do APL com Universidades e Centros de Pesquisa.

Tabela 2 - Comparativo dos Condicionantes Schumpeterianos entre Muriaé e São João Nepomuceno

\begin{tabular}{l|c|c}
\multicolumn{1}{c|}{ Condicionantes Schumpeterianos } & $\begin{array}{c}\text { Muriaé } \\
\text { (média) }\end{array}$ & $\begin{array}{c}\text { São João Nep. } \\
\text { (média) }\end{array}$ \\
\hline $\begin{array}{l}\text { Existência na região de elevado número de pessoas engajadas em atividades } \\
\text { de design e inovação de produto }\end{array}$ & 2,0 & 1,5 \\
\hline Elevado nível de qualificação da mão de obra & 2,0 & 2,0 \\
\hline Recorrentes trocas de pessoal entre fornecedores e usuários & 0,0 & 0,0 \\
\hline $\begin{array}{l}\text { Proximidade Universidades e Centros de pesquisa, encadeamentos a jusante, } \\
\text { a montante e horizontais extensivos }\end{array}$ & 0,0 & 2,5 \\
\hline $\begin{array}{l}\text { Presença de associações de classe e comerciais dedicadas à assistência de } \\
\text { rotina às atividades produtivas técnicas e produtivas, comerciais e } \\
\text { financeiras. }\end{array}$ & 3,0 & 3,0 \\
\hline Presença de associações dedicadas à qualificação da força de trabalho & 3,0 & 2,5 \\
\hline Presença de associações dedicadas à capacitação tecnológica às firmas & 3,0 & 3,0 \\
\hline Média dos pontos & $\mathbf{2 , 1 6}$ & $\mathbf{2 , 0 7}$ \\
\hline Fon
\end{tabular}

Fonte: Elaborado pelos autores.

\subsubsection{Condicionantes transacionais}

Em relação aos condicionantes Transacionais (Tabela 3), os APLs têm apresentado pontos restritivos. Apesar dos esforços da governança interna para ampliar a cooperação horizontal, existe baixa cooperação nas atividades de compras e vendas em conjunto, provocadas pelo baixo nível de confiança entre as empresas. Não existem grupos de exportação de peso, essas atividades são desenvolvidas por empresas isoladas que arcam com os custos burocráticos. O baixo nível de cooperação horizontal ocorre até mesmo nos grupos mais atuantes desses APLs, decorrente da concorrência acirrada vivida em décadas passadas.

Tem-se percebido maior presença da cooperação vertical. Em maior escala, essa cooperação ocorre por atividades de facção, bordados e estampagem, e, em menor escala, na etiquetagem, embalagem, costura, cós. Em São João Nepomuceno, ressalta-se a atividade de lavanderia. As demais atividades são racionalizadas, buscando escala interna de produção, não aproveitando as economias externas da aglomeração, por meio de especialização de atividades. Nas entrevistas, percebeu-se que, além da falta de confiança entre as empresas, os diferentes estágios tecnológicos têm dificultado

Revista de Administração e Inovação, São Paulo, v. 9, n.3, p. 231-256, jul/set. 2012. 
práticas de cooperação.

Em São João Nepomuceno, a proximidade entre empresas formais e informais é maior, pois, desde a década de 1980, as empresas informais surgiram como estratégia de ampliação da capacidade produtiva das empresas formais. Já em Muriaé, existe uma grande concorrência entre as empresas formais e informais.

Um dos problemas enfrentados pela governança local é o nível de participação dos empresários. Em Muriaé poucos empresários são filiados ao sindicato, assim a maioria fica fora do campo de atuação da governança interna. Em São João Nepomuceno, a maioria dos empresários é filiada, porém, há pouca participação efetiva dos empresários no arranjo.

Tabela 3 - Comparativo dos Condicionantes Transacionais entre Muriaé e São João Nepomuceno

\begin{tabular}{l|c|c}
\hline Condicionantes Transacionais & $\begin{array}{c}\text { Muriaé } \\
\text { (média) }\end{array}$ & $\begin{array}{c}\text { São João Nep. } \\
\text { (média) }\end{array}$ \\
\hline $\begin{array}{l}\text { Cooperação entre firmas competidoras baseada em relações de } \\
\text { confiança altamente desenvolvidas e sedimentadas. }\end{array}$ & 1,5 & 2,0 \\
\hline Presença de eficiência coletiva que reduz os custos de transação & 1,5 & 1,5 \\
\hline Utilização de colaboração vertical & 2,5 & 3,0 \\
\hline Utilização de colaboração horizontal & 1,0 & 1,0 \\
\hline Contatos frequentes entre empresas formais e informais & 2,5 & 3,0 \\
\hline Presença de confiança recíproca & 2,0 & 2,0 \\
\hline Menor rigor dos contratos padronizados & 3,0 & 2,0 \\
\hline $\begin{array}{c}\text { A Governança Interna (GI) do APL tem influenciado para facilitar } \\
\text { elaboração de contratos no sentido de maior flexibilidade }\end{array}$ & 2,5 & 1,5 \\
\hline A GI tem contribuído para facilitar o processo de compras & 2,0 & 1,0 \\
\hline A GI tem contribuído para facilitar o processo de vendas & 2,5 & 3,0 \\
\hline A GI tem contribuído para facilitar a distribuição e marketing & 2,5 & 2,5 \\
\hline Média dos pontos & $\mathbf{2 , 1 3}$ & $\mathbf{2 , 0 5}$ \\
\hline
\end{tabular}

Fonte: Elaborado pelos autores.

Dentro dos grupos atuantes de ambos APLs, a troca de informações não codificada, dos canais verticais e horizontais, é mais presente em Muriaé, já que existe um trabalho da governança interna em discussões para troca de informações. Em São João Nepomuceno, essa troca ocorre mais em nível vertical, principalmente, entre empresas formais e informais.

\subsubsection{Condicionantes institucionais}

Em relação aos condicionantes Institucionais, que visualizam a organização como parte integrante do sistema de relações de um setor social, ao qual está socialmente imersa, (Machado-daSilva, Fonseca \& Crubellate, 2005), percebe-se que os APLs possuem as mesmas condições para atuação. Existe o empenho dos agentes de animação e apoio para proporcionar um ambiente de menor

Revista de Administração e Inovação, São Paulo, v. 9, n.3, p. 231-256, jul/set. 2012. 
assimetria de informação e redução de custos de transação, estimulando o APL a se transformar em sistemas mais amplos de inovação. No entanto, o número reduzido de afiliados a esses agentes em Muriaé e a baixa participação nas reuniões em São João Nepomuceno têm dificultado o trabalho desses agentes. Em São João Nepomuceno, percebe-se ausência de apoio do poder público local. Em Muriaé há falta de proximidade do APL com instituições de pesquisa e ensino.

Tabela 4 - Comparativo dos Condicionantes Institucionais entre Muriaé e São João Nepomuceno

\begin{tabular}{l|c|c}
\multicolumn{1}{c|}{ Condicionantes Institucionais } & $\begin{array}{c}\text { Muriaé } \\
\text { (média) }\end{array}$ & $\begin{array}{c}\text { São João Nep. } \\
\text { (média) }\end{array}$ \\
\hline $\begin{array}{l}\text { Existência de um ambiente institucional que permite a redução da assimetria } \\
\text { de informação no APL e redução de custos de transação }\end{array}$ & 2,5 & 2,5 \\
\hline $\begin{array}{l}\text { A criação de aspectos culturais que permitam estabelecer laços de confiança, } \\
\text { interação social, identidade e objetivos comuns. }\end{array}$ & 2,0 & 2,0 \\
\hline $\begin{array}{l}\text { Existe apoio das instituições políticas e sociais locais no desenvolvimento de } \\
\text { atividades de parceria. }\end{array}$ & 3,0 & 2,5 \\
\hline $\begin{array}{l}\text { Existem apoios de instituições políticas e sociais para estimular a } \\
\text { transformação do APL em sistemas mais amplos de inovação (esforço } \\
\text { conjunto SEBRAE, FIEMG, Universidades, governo federal) }\end{array}$ & 2,5 & 2,5 \\
\hline $\begin{array}{l}\text { Proximidade dos APLs com instituições de ensino, pesquisa e agentes } \\
\text { econômicos }\end{array}$ & 0 & 2,5 \\
\hline Média dos pontos & $\mathbf{2 , 0}$ & $\mathbf{2 , 4}$ \\
\hline
\end{tabular}

Fonte: Elaborado pelos autores.

\section{CONSIDERAÇÕES FINAIS}

O presente estudo é uma investigação sobre Sistemas Territoriais de Produção, objetivando aprofundar questões específicas sobre a formação, a estruturação e o desenvolvimento de APLs. Para isso, foram estudados dois APLs da Indústria de Confecção: Muriaé e de São João Nepomuceno. A coleta de dados foi realizada por técnicas de pesquisa bibliográfica, pesquisa documental, entrevista semiestruturada e entrevista estruturada.

A verificação da origem dos APLs revela que estes foram induzidos por economias externas locais, provenientes de uma firma inicial estruturada verticalmente. A ampliação das atividades se deu pela abertura de empresas por ex-empregados da produção da empresa inicial, que usaram seus próprios recursos financeiros e conhecimentos. Como resultado, houve aumento do fluxo de serviços ligados à atividade-fim e também de serviços mais genéricos.

Apesar de se poder identificar um modelo de trajetória territorial para os APLs estudados, e até mesmo uma estrutura de funcionamento comum, cada um possui características próprias em relação aos agentes envolvidos, à forma de interação desses agentes no território e aos produtos resultantes. A

Revista de Administração e Inovação, São Paulo, v. 9, n.3, p. 231-256, jul/set. 2012. 
aglomeração de firmas na mesma região desencadeia retornos crescentes, provenientes de economias internas e externas.

No início, os condicionantes para surgimento dos APLs foram Marshallianos, criados pelas empresas pioneiras. Todavia, esses condicionantes não garantem o desenvolvimento da territorialização. Assim, outras externalidades locais foram desenvolvidas, em virtude da necessidade de gestão conjunta com a participação de organizações de animação e apoio, formando as externalidades Schumpeterianas, Transacionais e Institucionais. As primeiras envolvem a criação de um ambiente inovativo, com base na aprendizagem e no desenvolvimento por meio de um processo evolutivo; as segundas visam à maior interação entre as firmas, por meio da redução dos custos de transação; e as últimas estão relacionadas com as modificações no ambiente institucional em que os APLs estão inseridos, de modo a construir um ambiente que valorize a interação social e estreite os laços de confiança mútua.

Destaca-se que há vários pontos comuns entre os APLs estudados que podem fazer parte de outros APLs: a) fraca cooperação vertical e horizontal; b) baixo contato com centros de pesquisa; c) problemas com a localização de fornecedores, ausência de cadeia produtiva completa; d) ausência ou baixa exportação para o mercado nacional e internacional; e) baixa participação nas entidades de animação e apoio pela filiação e frequência nos encontros; f) falta de confiança entre os agentes; $h$ ) falta de um papel definido do governo local.

Desse modo, políticas de apoio aos APLs, como instrumento de planejamento e desenvolvimento, devem ultrapassar os limites de uma política industrial local em direção a uma política de desenvolvimento regional, considerando também as questões relacionadas com desenvolvimento do urbano e da área de entorno. Isso é necessário para que não se criem ilhas de desenvolvimento produtivo incapazes de integrar o todo regional e nem que se promovam APLs sem dinamismo, comprometendo a sua sobrevivência no longo prazo.

As limitações identificadas pela pesquisa servem como sugestões para novos estudos, tais como: a) identificação do efeito nas características dos APLs, de condicionantes institucionais externos (exigências de legislações ambientais, Política Macroeconômica e Sistema Nacional de Inovação); b) avaliação de ações dos agentes territoriais de mudança confrontando finalidade, objetivos, metas e resultados das ações de trabalho; c) avaliação da opinião dos empresários locais sobre o papel dos agentes de mudança; d) identificação dos motivos da falta de cooperação; e) identificação dos fatores que podem contribuir para aumento da participação efetiva dos empresários locais nas entidades de animação e apoio.

Revista de Administração e Inovação, São Paulo, v. 9, n.3, p. 231-256, jul/set. 2012. 


\section{REFERÊNCIAS}

Amato, J., Neto. (2000). Redes de cooperação produtiva e clusters regionais: oportunidades para as pequenas e médias empresas. São Paulo: Atlas.

Balestrin, A., Verschoore, J. R., \& Reyes, E., Jr. (2010). O campo de estudo sobre redes de cooperação interorganizacional no Brasil . Revista de Administração Contemporânea, 14(3), 458-477.

Barros, A. J. S., \& Lehfeld, N. A. S. (2000). Fundamentos de metodologia científica: um guia para iniciação científica (2a ed.). São Paulo: Makron Books.

Black, J. A., \& Champion, D. J. (1976). Methods and issues in social research. New York: John Wiley \& Sons.

Britto, J. (2002). Cooperação interindustrial e redes de empresas. In D. Kupfer, \& L. Hasenclever (Orgs.), Economia industrial: fundamentos teóricos e práticas no Brasil (pp. 245-388). Rio de Janeiro: Campus.

Campos, R. R., Cário, S.A. F., \& Nicolau, F.A. (2000). Arranjo produtivo têxtil: vestuário do Vale do Itajaí/SC. Florianópolis: BNDES.

Cassiolato, J. E., \& Lastres, H. M. M. (2003). O foco em arranjos produtivos e inovativos locais de micro e pequenas empresas. In H. M. M. Lastres, J. E. Cassiolato, \& M. L. Maciel (Orgs), Pequena empresa: cooperação e desenvolvimento local (pp. 21-34). Rio de Janeiro: Relume Dumará.

Ceglie, G., \& Dini, M. (1999). SME cluster and network development in developing countries: the experience of UNIDO. Viena: UNIDO.

Crocco, M., Santos, F., Simões, R., \& Horácio, F. (2001). O arranjo produtivo moveleiro de Ubá-MG. In L. F.TIRONI (Org.), Industrialização centralizada: sistemas industriais locais (Vol. 1, pp. 179236). Brasília: IPEA.

Cunha, C. R., \& Carrieri, A. P. (2003). Mapeando as relações interorganizacionais na teoria organizacional: garimpando os principais periódicos brasileiros sobre gestão. Anais do Encontro Nacional da Associação Nacional de Pós-Graduação e Pesquisa em Administração, Atibaia, SP, Brasil, 27.

Cunha, I., Pereira, M. C. S., \& Casarotto, N. C., Filho. (2006). Análise da competitividade das principais aglomerações produtivas de móveis da região sul do Brasil. Florianópolis: BRDE.

Fonseca, H. P., Netto. (2002). Análise e avaliação de sistemas territoriais de produção e inovação organizacional (Relatório de Pesquisa/2002). Rio de Janeiro: Faperj.

Garcez, C. M. D. (2003). Empresas multinacionais em sistemas locais de inovação no Brasil: o caso da indústria automobilística. (Tese de Doutorado). Universidade Federal do Rio de Janeiro, Rio de Janeiro, RJ, Brasil.

Haddad, P. R. (1989). Economia regional: teorias e métodos de análise. Fortaleza: BNB.

Revista de Administração e Inovação, São Paulo, v. 9, n.3, p. 231-256, jul/set. 2012. 
Hirschman, A. (1958). The strategy of economic development. New Haven: Yale INRA.

Jarillo, J. C. (1988). On strategic networks. Strategic Management Journal, 9(1), 31-41.

Kraemer, F. B. (2007). Centro-norte fluminense do Estado do Rio de Janeiro. In F. G. Tenório (Org.), Cidadania e desenvolvimento local (pp. 273-340). Rio de Janeiro: FGV.

Krugman, P. (1991). Geography and trade. Cambridge, MA: The MIT Press.

Krugman, P. (1996). Development, geography and economic theory. Cambridge, MA: The MIT Press.

Lemos, C. (2003). Micro, pequenas e médias empresas no Brasil: novos requerimentos de políticas para a promoção de sistemas produtivos locais. (Tese de Doutorado). Universidade Federal do Rio de Janeiro, Rio de Janeiro, RJ, Brasil.

Lemos, M. B., Santos, F. B, \& Crocco, M. (2005). Arranjos produtivos locais sob ambientes periféricos: os condicionantes territoriais das externalidades restringidas e negativas. In C. C. Diniz, \& M. B. Lemos (Org.), Economia e território (pp. 171-205). Belo Horizonte: UFMG.

Machado-da-Silva, C. L., Fonseca, V. S., \& Crubellate, J. M. (2005). Unlocking institutionalization process: insights for an institutionalizing approach. Brazilian Administration Review, 2(1), 1-20.

Maia, K. (1994). Confecções em Cianorte: um distrito industrial? (Dissertação de Mestrado). Universidade Federal do Paraná, Curitiba, PR, Brasil.

Malhotra, N. K. (2001). Pesquisa de marketing: uma orientação aplicada (3a ed.). Porto Alegre: Bookman.

Markusen, A. (1996). Sticky places in slippery space: a typology of industrial districts. Economic Geography, 2(1), 293-313.

Marshall, A. (1983). Princípios de economia (Os Economistas). São Paulo: Abril Cultural.

Mytelka, L., \& Farinelli, F. (2000). Local clusters, innovation systems and sustained competitiveness (UNU/INTECH Discussion Papers). Maastricht: United Nations University.

Piore, M. J., \& Sabel, C. F. (1984). The second industrial divide: possibilities for prosperity. New York: Basic Books.

Podolny, J., \& Page, K. (1998). Networks forms of organization. Annual Reviews Sociological, 24, 5776.

Polèse, M. (1998). Economia urbana e regional: lógica espacial das transformações económicas. Coimbra: APDR.

Ribault, M., Martinet, B., \& Lebidois, D. (1995). A gestão das tecnologias (Coleção Gestão \& Inovação). Lisboa: Dom Quixote.

Richardson, R. J. (2007). Pesquisa social: métodos e técnicas. São Paulo: Atlas.

Triviños, A. N. S. (1987). Introdução à pesquisa em ciências sociais. São Paulo: Atlas.

Revista de Administração e Inovação, São Paulo, v. 9, n.3, p. 231-256, jul/set. 2012. 
Verschoore, J. R., \& Balestrin, A. (2008a). Fatores relevantes para o estabelecimento de redes de cooperação entre empresas do Rio Grande do Sul. Revista de Administração Contemporânea, 12(4), 1043-1069.

Verschoore, J. R., \& Balestrin, A. (2008b). A participação em redes de cooperação influencia os resultados das pequenas e médias empresas associadas?. Anais do Encontro Nacional da Associação Nacional de Pós-Graduação e Pesquisa em Administração, Rio de Janeiro, RJ, Brasil, 32.

${ }^{1}$ Embora Marshall nunca tenha mencionado o termo espaço em seus escritos 


\title{
TERRITORIAL RESTRICTIONS FOR TRAINING, DEVELOPMENT AND STRUCTURE OF LOCAL PRODUCTIVE ARRANGMENTS: A COMPARATIVE STUDY OF PLAs IN THE CLOTHING INDUSTRY IN THE MINAS GERAIS STATE
}

\begin{abstract}
This research focuses on the Territorial Production Systems in local clusters production of Minas Gerais, delving into the formation of these companies and their development into regional clusters, to show how these territories were structured. The territorial conditions Marshallian, Schumpeterian, Transactional and Institutional were used as a theoretical framework. Qualitative research of a descriptive study was completed as well as the corpus of APL Muriaé and São João Nepomuceno. Data collection was performed by means of literature and documentary review which was both semistructured and structured in nature. Through this work, it was possible to identify APLS originally from an initial vertical company. Despite the identification of a trajectory model for the territorial clusters studied, each one has specific characteristics on the number of players involved and the manner of interaction of the territory. At first, the conditions for the emerging APLs were related to Marshallian externalities, created by the pioneers. Over time, other externalities emerged: Schumpeterian, to create an innovative environment; Transaction, the search for greater interaction among companies by reducing transaction costs; and Institutional related changes in the institutional environment in which the clusters are embedded.
\end{abstract}

Key-words: SMEs; Local Productive Arrangements; Territorial externalities.

Data do recebimento do artigo: 22/04/2012

Data do aceite de publicação: 18/08/2012

Revista de Administração e Inovação, São Paulo, v. 9, n.3, p. 231-256, jul/set. 2012. 